\title{
Geostatistical mapping and spatial variability of surficial sediment types on the Beaufort Shelf based on grain size data
}

\author{
K. Jerosch * \\ Geological Survey of Canada (Atlantic), Bedford Institute of Oceanography, P.O. Box 1006, Dartmouth, Nova Scotia, Canada B2Y 4A2
}

\section{A R T I C L E I N F O}

\section{Article history:}

Received 4 July 2011

Received in revised form 14 February 2012

Accepted 23 February 2012

Available online 3 March 2012

\section{Keywords:}

Canadian Arctic

Beaufort Shelf

Sediment textures

Grain size

Geostatistics

Cokriging

Ordinary kriging

\begin{abstract}
A B S T R A C T
The paper describes an approach for a quality controlled mapping of grain sizes and sediment textures for the Beaufort Shelf in the Canadian Arctic. The approach is based on grain size data collected during the Nahidik Program (2005-2009) and earlier. A replenishment of grain size data since the 1980s, as well as the consideration of correlating parameters (bathymetry, slope and sediment input) to a cokriging algorithm, amends the former way of mapping the surficial sediments of the Beaufort Shelf. The cokriging analysis showed that the simulation of a sediment input by the Mackenzie River, modeled as a cost-distance function, was the key variable in reducing the errors of the output estimate.

Furthermore, the approach compares the geostatistical interpolation methods of ordinary kriging and cokriging and recommends the use of a combination of both. The predicted mean standard errors showed that in this study cokriging was the superior interpolation method for clay, silt and sand while ordinary kriging was more suitable for gravel.

A new sediment texture map, based on the grain size maps, is provided according to commonly used grain size and sediment type classification systems.
\end{abstract}

(c) 2012 Elsevier B.V. All rights reserved.

\section{Introduction}

The nearshore Beaufort Sea is a sensitive marine environment that is also the focus of oil and gas exploration. Offshore, the Beaufort Sea contains large potential reserves of hydrocarbons. Any future exploitation of these resources will present unique engineering challenges and will require an understanding of the processes that govern stability, nearshore morphology and sediment properties in the extensive shallow coastal zone of the Beaufort Shelf. Knowledge of the surficial sediment distribution is, therefore, necessary to provide a framework for understanding sediment stability, sediment transport, platform foundation conditions and to balance engineering challenges with environmental concerns, resource development and precautionary sustainable management. Management of offshore resources has always been constrained by a lack of high-quality information on the marine ecosystem. However, additional surficial grain size data coupled with precise positioning using Global Positioning System technology, and the utilization of new and contextual analysis methods provides an innovative method of gaining information over wide areas of the Beaufort seafloor.

The Canadian Beaufort Sea (Fig. 1) is an extremely dynamic environment susceptible to reworking by both arctic marine and periglacial processes. Its sediments are subjected to many of the normal processes affecting temperate latitude sediments, such as wave action, tides and

\footnotetext{
* Alfred Wegener Institute for Marine and Polar Research, Am Handelshafen 12 27570 Bremerhaven, Germany. Tel.: + 499024267059.

E-mail address: kjerosch@awi.de.
}

storm surges as well as many uniquely arctic processes, such as ice push, thermo-erosion and thaw subsidence. In addition, normal offshore processes may be strongly modified by the uniquely arctic nature of the system; for example, the presence of offshore sea ice limits wave activity and even during the short open-water season, offshore ice affects the fetch window available for wind-wave generation (Harper, 1990).

The erosional nature of the Mackenzie delta front and the drowned morphology indicate that the delta is undergoing transgression, resulting in minimal water depths for sediment accumulation (Hill et al., 2001). However, bar accretion still occurs within large embayments at the mouths of some distributary channels (Jenner and Hill, 1998). In general, the nearshore area (seaward of the Holocene delta) is very shallow. Water depths are less than $2 \mathrm{~m}$ at distances in excess of $15 \mathrm{~km}$ from the shore. Mean tides are $0.3 \mathrm{~m}$ and large tides are up to $0.5 \mathrm{~m}$, whereas winds may raise water levels as much as $2.4 \mathrm{~m}$ (Hill et al., 2001) or lower them by up to $1 \mathrm{~m}$ (Henry, 1975).

According to Pelletier (1984) fine-grained sediments occupy most of the seabed, particularly in the central part of the southern Beaufort Shelf and seaward of the $10 \mathrm{~m}$ isobath. This is the area of clay deposition and indicates relatively low hydrodynamic conditions. Silt is found chiefly from the $10 \mathrm{~m}$ isobath landward into the nearshore, from Mackenzie Bay to Kugmallit Bay in the east. Sand is common along the eastern edge of Mackenzie Trough, in the coastal zone, seaward of the $2 \mathrm{~m}$ isobath, and on bars, spits and offshore islands, due to increased sorting action by waves and currents which remove finer sediments. A considerable amount of sand deposition occurs on the eastern portion of the 


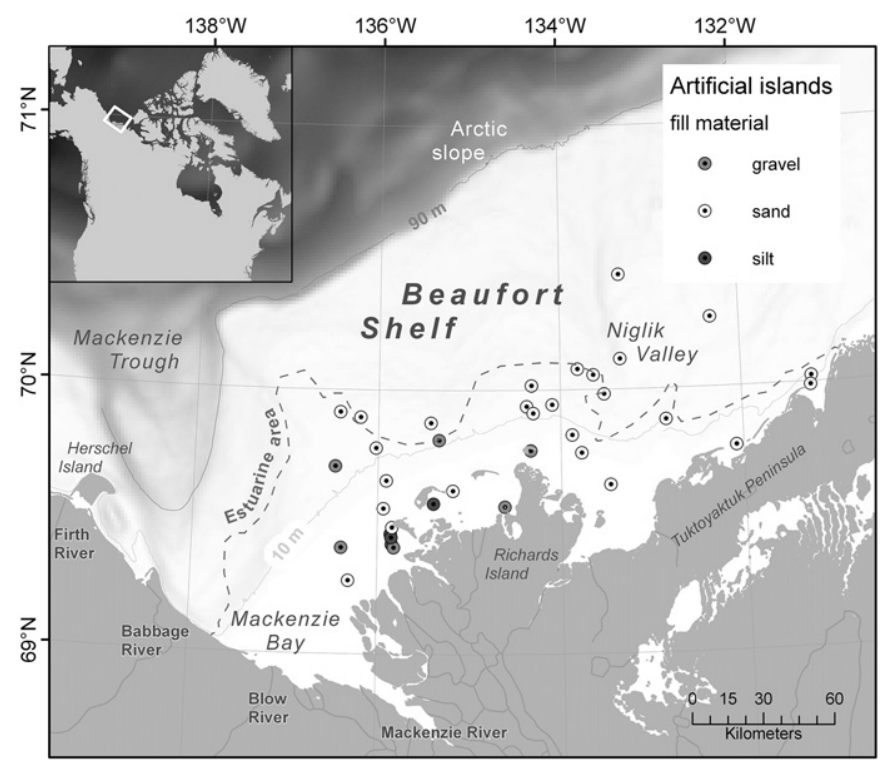

Fig. 1. Location map of the Canadian Beaufort Shelf showing the distribution and fill material of artificial islands. The textural dots refer to artificial islands.

shelf where some erosion by bottom currents exposes older beach deposits (Pelletier, 1984). Gravel is also common in this area, but is found in much higher quantities along bars, beaches and at the base of coastal cliffs undergoing erosion. The offshore sand and gravel deposits west of Herschel Island are due mainly to ice-rafting. Here, sediments are deposited from ice impeded by the winter freeze-up and impinged against western Herschel Island. Isolated occurrences of sand and gravel on the outer shelf, to the east, may also be due to ice-rafting (Pelletier, 1984).

Most of the sediment is deposited from the Mackenzie, Firth, Babbage and Blow Rivers. A sediment plume defining an estuarine zone (Fig. 1) extends about 55 to $70 \mathrm{~km}$ north of the coastline. The Mackenzie River is the largest river on the North American side of the Arctic with an annual freshwater discharge of $330 \mathrm{~km}^{3}$ and an annual sediment load of $127 \mathrm{Mt}$ to the Canadian Beaufort Shelf (Macdonald et al., 1998). Massive quantities of predominantly fine-grained sediment and associated organic carbon are transported into the Arctic Ocean during the freshet from May to September (Forest et al., 2007; Hill et al., 1991; Walker et al., 2008). Under the influence of the Coriolis force, this plume moves easterly, and sediments derived from coastal erosion on the seaward fringes of the estuary and Tuktoyaktuk Peninsula may be entrained in this system. West of Shallow Bay, sediment movement in the nearshore is also controlled by coastal currents (Pelletier, 1984). O'Brien et al. (2006) note that the Mackenzie River is the largest source of sediment to the arctic region; therefore the discharge of the Mackenzie River is the major

Table 1

Sediment grain size data used for geostatistical interpolation (1969-2008).

\begin{tabular}{llc}
\hline $\begin{array}{l}\text { Year of } \\
\text { sampling }\end{array}$ & Reference & $\begin{array}{c}\text { Number of } \\
\text { samples }\end{array}$ \\
\hline $1969-2008$ & Expedition Database (ED) (2010) & 1114 \\
1976 & $\begin{array}{l}\text { EBA Engineering Consultants Ltd. and Beaufort-Delta Oil } \\
\text { Project Limited (1976) }\end{array}$ & 42 \\
1976 & $\begin{array}{l}\text { Samples located using offsets from transponder; } \\
\text { locations found in a field notebook provided by Dr. H. }\end{array}$ & 22 \\
& Kerfoot (1976). & 13 \\
1987 & Kauppaymuthoo (1997) & 49 \\
1970 & Dewis (1971) & 1240 \\
$1969-2008$ & & \\
\hline
\end{tabular}

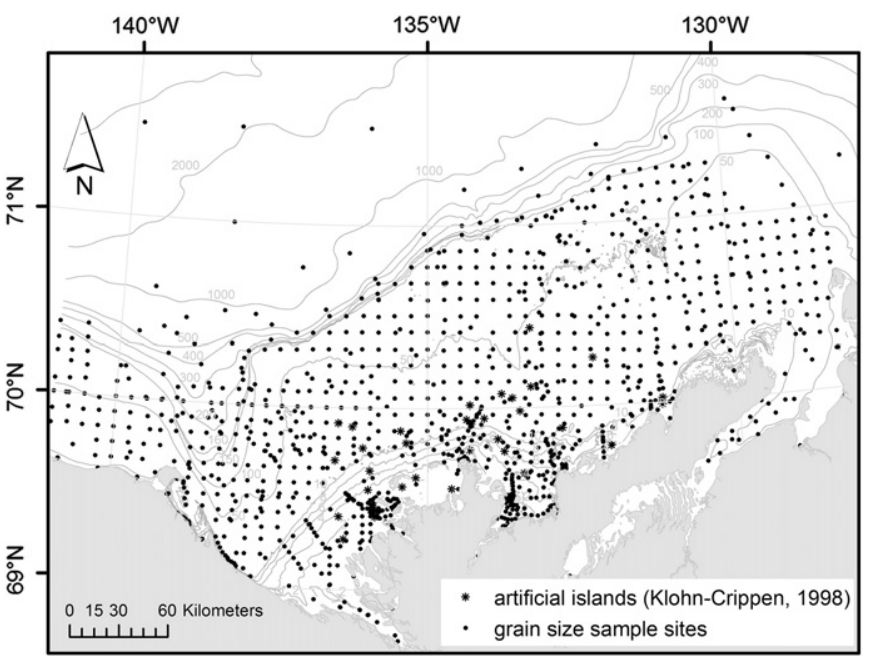

Fig. 2. Spatial data distribution of grain size samples and artificial islands according to Klohn-Crippen (1998).

component for the geostatistical modeling of Beaufort Shelf sediments. The goals of this study are:

- to use and describe an appropriate interpolation method achieved by comparing ordinary kriging and cokriging

- to deliver quality controlled results by predicted standard errors of each sediment class

- to provide a series of new georeferenced grain size maps and a sediment texture map of the Beaufort Shelf based on geostatistical interpolation.

\section{Material and methods}

Realistically, it is impossible to get exhaustive values of data at every location because of practical constraints. Thus, interpolation is fundamental to the graphing, analysis and understanding of 2D data. Different possibilities exist to describe the relationships (autocorrelations) of punctual data. They are based on the assumption that the autocorrelation of the data is not dependent on the absolute (geometrical) location of the sites, but on the spatial distribution of the sites relative to each other in distance and direction (Isaaks and Srivastava, 1992). Geostatistical methods like kriging (Krige, 1951; Matheron, 1963) include the degree of spatial autocorrelation and the directional dependency (anisotropy) when predicting measurements. The degree of spatial autocorrelation can be assessed by applying variogram analysis, where semivariances are calculated for defined distance classes and plotted against the separation distance. The resulting experimental variogram and cross-validation analysis are then the basis for finding an adequate variogram model that may be used for the kriging

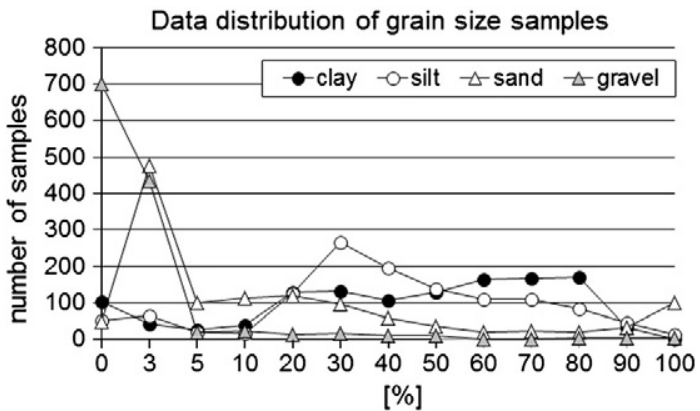

Fig. 3. Data distribution of the clay, silt, sand and gravel components of grain size samples, classified after Wentworth (1922), plotted against the total number of samples (1240) used in this study. 


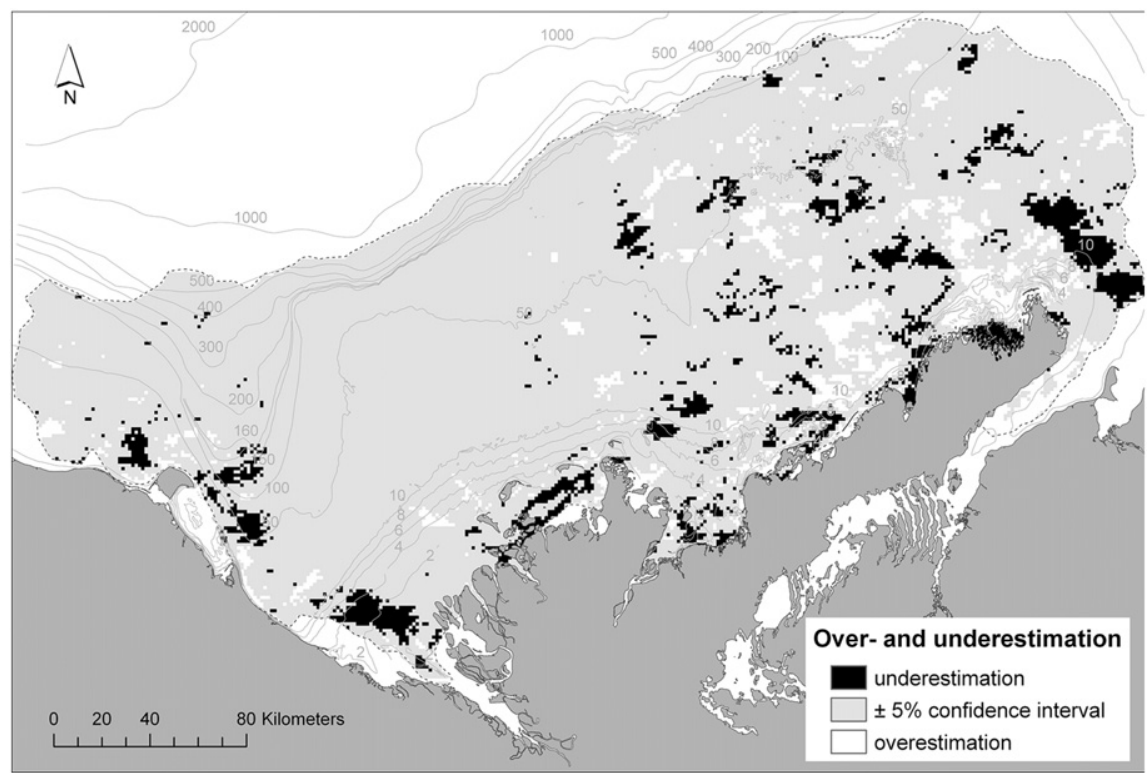

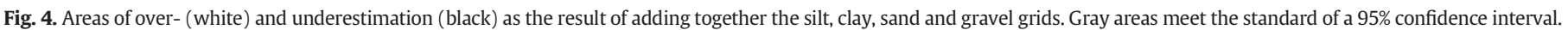

algorithm. Applying cross-validation, each measurement value is extracted from the dataset and estimated by kriging based on the selected variogram model. By subtracting each measured value from its estimated value an estimation or cross-validation error can be calculated resulting in an error distribution for the whole dataset; for e.g. the mean standardized error (MSE - the standardized average value of the cross-validation errors which at best should be 0 ), the root mean square standardized error (RMSSE - ratio of mean squared cross-validation errors and the kriging variances which at best should equal 1) and the correlation coefficient after Spearman $\left(\mathrm{C}_{\mathrm{S}}\right.$ - in case of an ideal correlation the $\mathrm{C}_{\mathrm{S}}$-value should equal 1 , if no such correlation exists $C_{S}$ tends towards 0 ) (for a detailed description please refer to Pesch et al., 2008).

The predicted standard errors (PSEs) measure the accuracy of predictions made with a regression line. If the prediction errors are unbiased, the mean prediction error should be near zero. The PSEs express the maximum deviation of the real values and therefore show how much variation is expected in the predictions. Like the cross-validation, the PSEs are an estimate for prediction quality of the interpolation. Cokriging is based on the kriging algorithm and provides a superior estimation of map values, if a secondary variable (in this study for instance bathymetry) is sampled more intensely than the primary variable (grain size) (Davis, 2002; Goovaerts, 1997). The availability of grain size data is limited and cokriging could improve its interpolation estimates.

The majority of the grain size data used in this study are stored in the Expedition Database (ED) of Natural Resources of Canada (NRCan), Geological Survey of Canada, Atlantic (GSCA) and include data from box cores and the upper part of piston cores. More than 100 samples were collected during the Nahidik Program. A compilation of grain size data sampled during the period 1969-2008 is presented in Table 1.

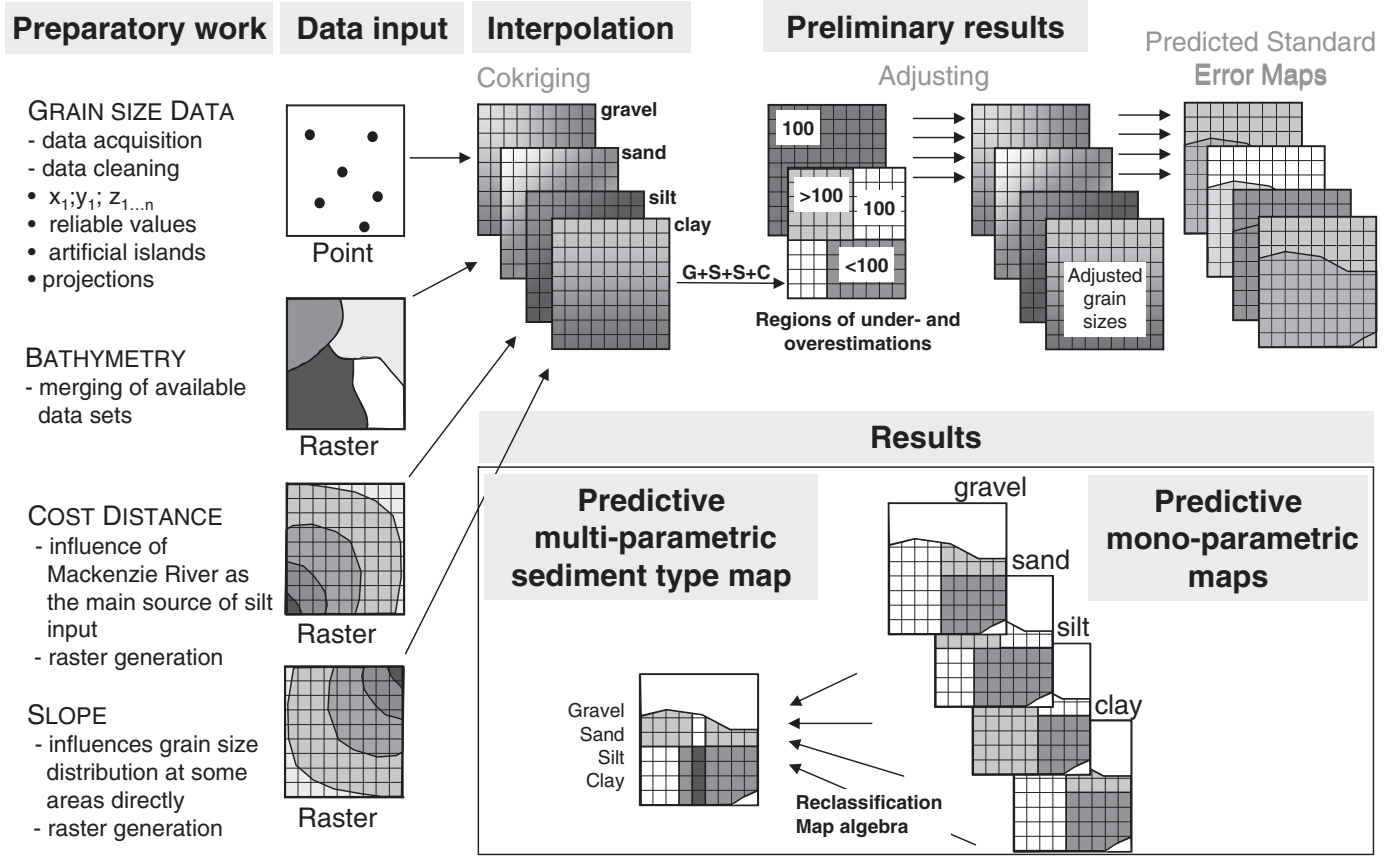

Fig. 5. The process for the generation of a sediment texture map for the Beaufort Shelf applying cokriging. 

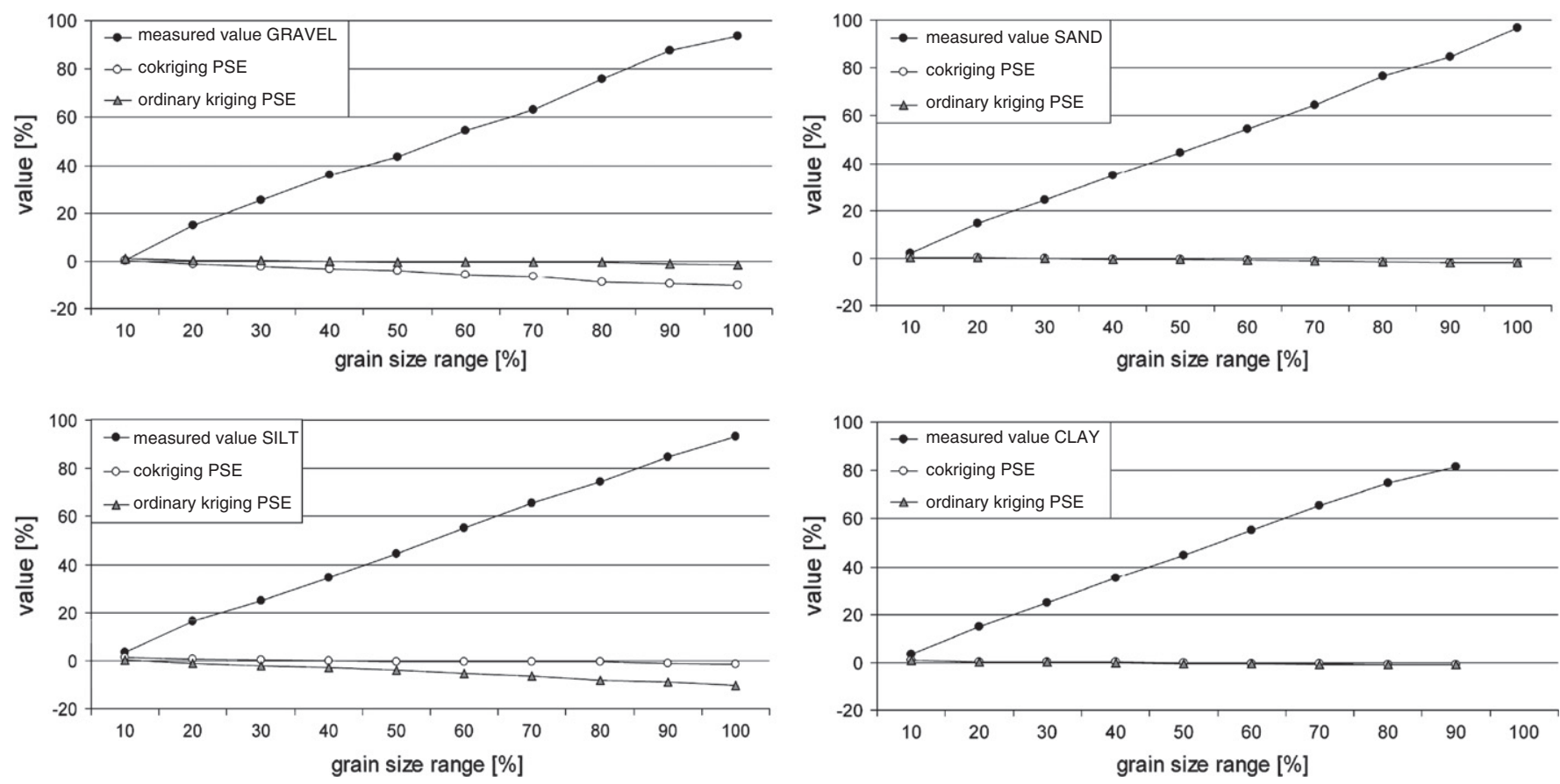

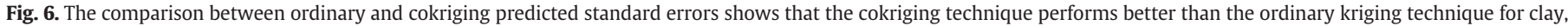
silt and sand.

Three cokriging parameter maps were utilized: 1 . a bathymetry map was merged based on unpublished data provided by NRCan and the Canadian Hydrographic Service (1986), 2. a slope map was derived from the bathymetry raster assuming that slope influences grain size distribution directly, and 3. a cost distance grid was created to simulate the influence of the Mackenzie River as a significant source of silt.

Cost distance tools in ArcGIS (ESRI) were used to calculate the lowest accumulative cost (or in this application - distance) for each cell in order to reach the source (or in this application - the Mackenzie River mouth). In contrast with the simple geometric and straight-line Euclidean distance, the cost distance tools take into account that distance can also be dependent on travel cost and that cost can vary with factors such as terrain and ground cover. Considering this study, water currents and land masses such as Langley Island influence the sediment distribution supplied by the Mackenzie River. Using the cost raster, the source of sediment input (Mackenzie Delta) and the sediment transport are simulated. The cost distance function produces an output raster. Each cell is assigned a value that represents the lowest accumulative distance of getting back to the source.

\section{Calculation}

The data input was built by extensive pre-processing of the sediment data set. The process consisted of data acquisition, data cleaning and projecting (Universal Transverse Mercator (UTM) zone $8 \mathrm{~N}$ and North American Datum of 1927 (NAD27)). Data without confirmed references, data proximal to artificial islands according to Klohn-Crippen (1998) (see Fig. 2) and outliers were deleted. Furthermore, this study required data sets with a minimum data resolution comprised of gravel, sand, silt and clay percentages. Finally, a data set of 1240 sample sites fulfilled all requirements (see Fig. 2).

The process of cokriging generated predictive mono-parametric maps for the surficial grain size ranges gravel, sand, silt and clay. For interpolation purposes, the samples were classified on the basis of Wentworth's (1922) grain size classification where gravel is $>2000 \mu \mathrm{m}$; sand is $2000 \mu \mathrm{m}$ to $62.5 \mu \mathrm{m}$; silt is 62.5 to $3.91 \mu \mathrm{m}$, and clay is $<3.91 \mu \mathrm{m}$. Fig. 3 presents the frequency distribution of the grain size classes.
Shephard's (1954) classification system was then applied to the mono-parametric maps by using reclassification and raster calculations to generate a multi-parametric sediment type map. This classification system is simple, practical, has a wide application and groups sediments into useful categories that make the presentation of textural data effective.

In order to apply Shephard's (1954) classification system to the interpolated grain size maps, the sum of the four grain size values (percentages) should equal 100. But this is not always the case with the kriging algorithm. Regions of slight over- and underestimation can appear due to the general functioning of the kriging algorithm (see Fig. 4). The kriging algorithms do not stop interpolating when they reach values of 0 or $100 \%$. Under the assumption of spatial autocorrelation (near samples are more related to each other than distant samples), characteristics at proximal locations appear to be correlated it is possible for the kriging algorithm to calculate an over- or an underestimation for the predicted values. We assume, for instance, a row of spatially distributed values close to 100 (e.g. 80; 85; 99) will be used to predict a value at an unsampled location; and we assume further, that no other data point is located within the range of influence according to the variogram analysis. If these values are located closely to each other while the unsampled site is positioned either at the same distance or further away, the predicted value would reach values above 100 . Therefore, each grain size grid was standardized using a " $100 \%$-grid" (cell values $=100$ ) as follows: grain size grid $_{\text {standardized }}=$ grain size grid/over-underestimation grid $\times 100 \%$-grid.

The mono-parametric grids of sand, silt and clay were reclassified into four percentage classes: $0-25 \%, 25-50 \%, 50-75 \%$ and $75-100 \%$ and the gravel grid reclassified into two classes: $0-10 \%, 10-50 \%$ (no values higher than $50 \%$ occurred in the dataset).

The final product of a multi-parametric sediment type map, providing the percentages of three grain sizes in each cell according to Shephard (1954) required the combination of the mono-parametric maps of sand, silt and clay. The gravel layer is provided separately according to Shephard's (1954) second ternary diagram which classifies the composition of gravel, sand and mud. The full process to generate the sediment texture map of the Beaufort Shelf is summarized in Fig. 5. 


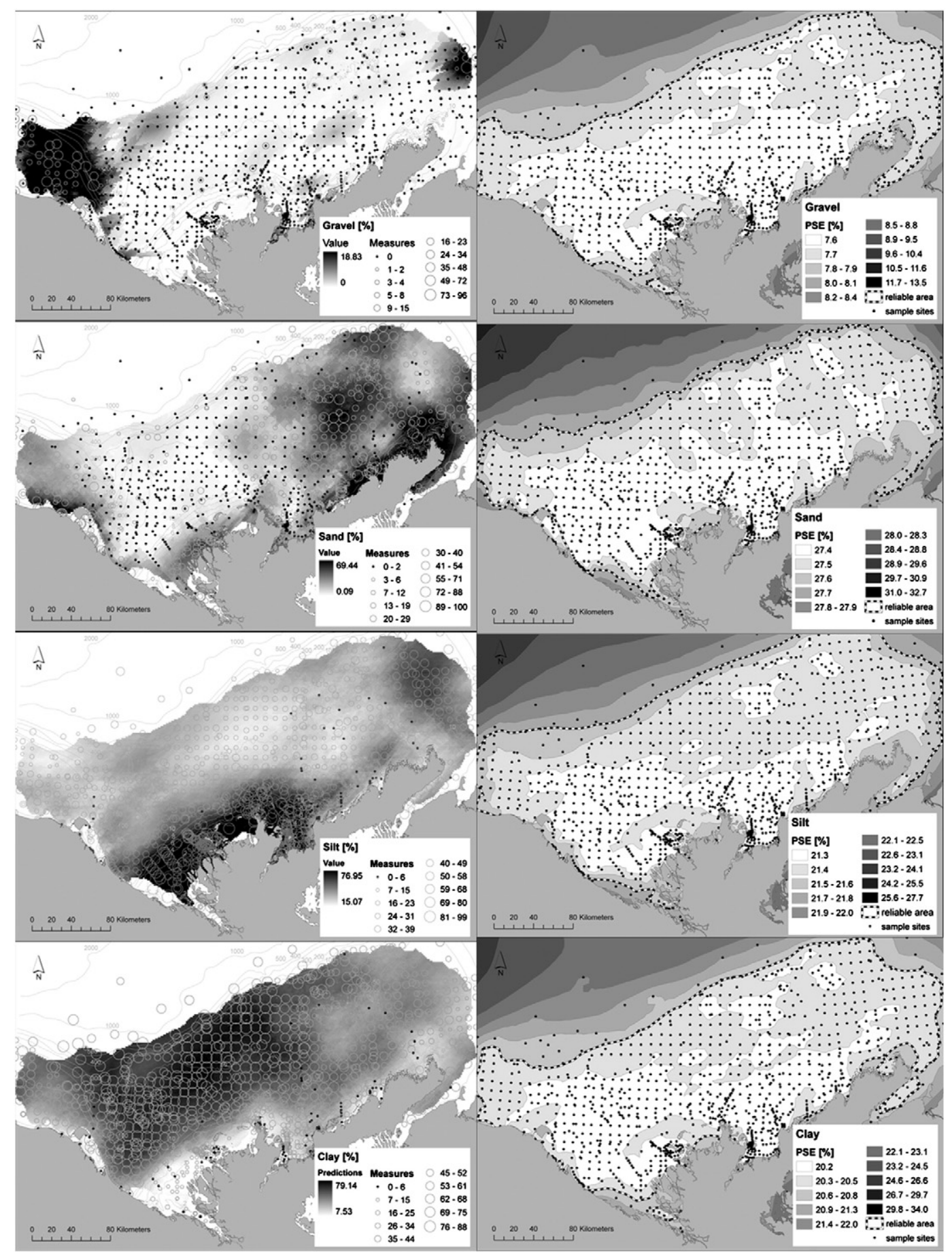

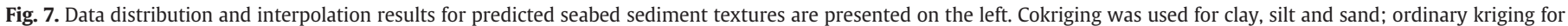
gravel. The predicted standard error (PSE) maps on the right were used to define the reliable extent of the interpolation area.

\section{Results and discussion}

\subsection{Comparison of ordinary kriging and cokriging}

Subsequent to data processing and applying autocorrelation, four single grids (clay, silt, sand and gravel) were generated by ordinary kriging and cokriging. Cokriging also considered parameters that influence sediment texture such as bathymetry, slope, cost distance from the Mackenzie River and anisotropy (directional dependency). To assess the quality of the surface estimations key parameters were calculated from the results of cross-validation. The MSE, RMSSE, $C_{S}$ as well as the nugget-sill ratio values are listed in Table 3. MSE shows that the average cross-validation errors equal almost zero in all cases. RMSSE equals almost 1 for all parameters indicating that variances calculated from the cross-validation errors by average equal the theoretical kriging variances. In all other cases, except sand, the $\mathrm{C}_{\mathrm{S}}$ lies above 0.8 indicating high degrees of associations between the measured and estimated values. With the exception of sand and the cokriging result for gravel, the nugget-sill ratios lie below 0.5 which is indicative for low smallscale variances and strong autocorrelations of the measurement values. For all grain sizes besides gravel, the MSE and the RMSSE can be observed to be improved by applying cokriging, when compared with ordinary kriging. A comparison between ordinary kriging PSEs and cokriging PSEs showed that the cokriging technique achieved considerably 


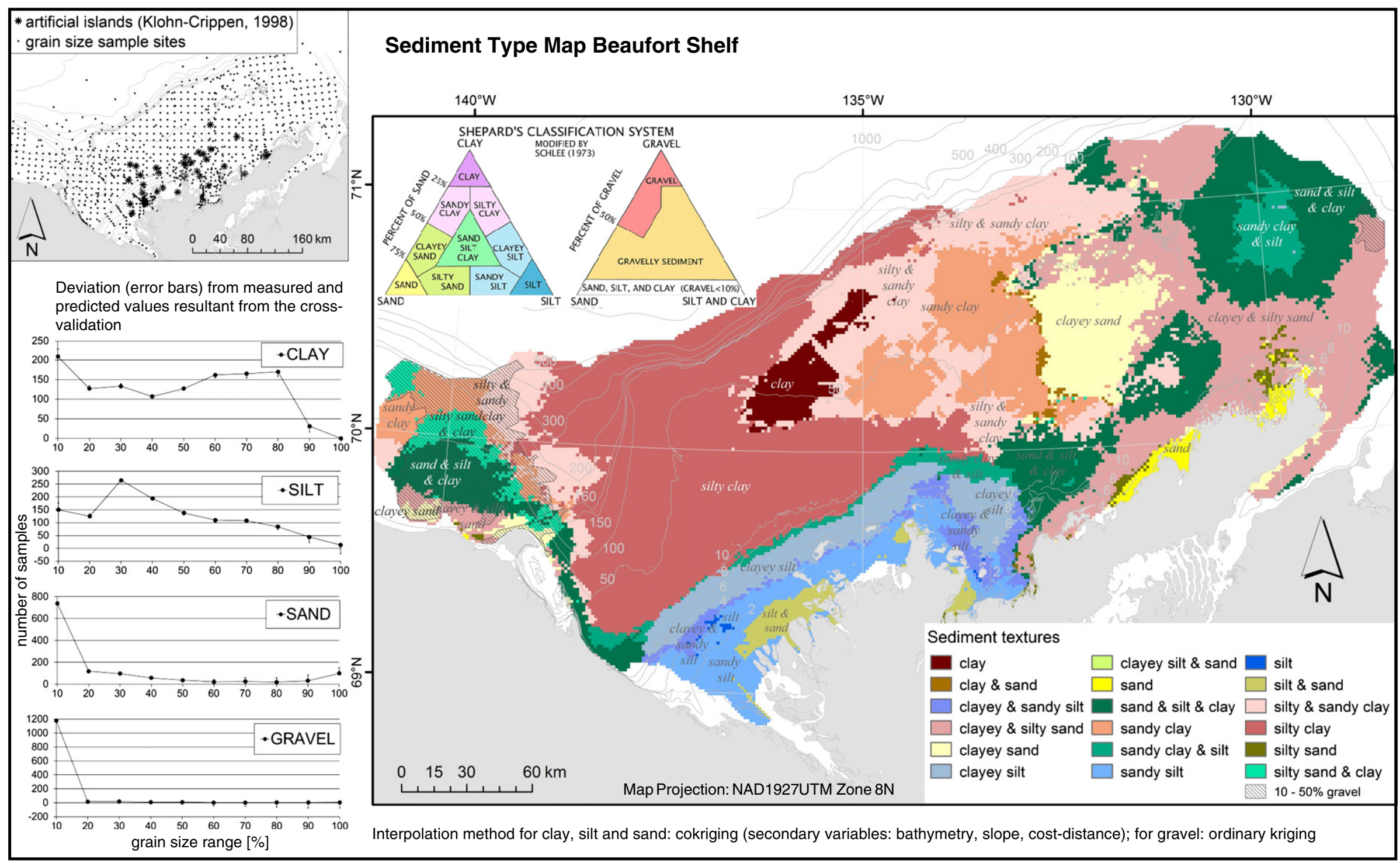

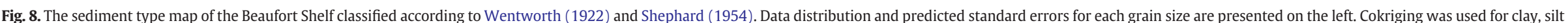
and sand; ordinary kriging for gravel. See Table 2 for the grain size percentage composition for each sediment type. 
Table 2

Areas of sediment types $\left(\mathrm{km}^{2}\right)$ and their grain size composition in percentages as they are presented in the sediment type map of the Beaufort Shelf in Fig. 8. The largest contiguous area is covered by silty clay which is $22.7 \%$ of the total area $\left(67,185.38 \mathrm{~km}^{2}\right)$.

\begin{tabular}{lrrrr}
\hline Sediment type & Clay [\%] & Silt [\%] & Sand [\%] & Area $\left[\mathrm{km}^{2}\right]$ \\
\hline Clay & $75-100$ & $0-25$ & $0-25$ & 1246.34 \\
Silty clay & $50-75$ & $25-50$ & $0-25$ & $15,257.75$ \\
Sandy clay & $50-75$ & $0-25$ & $25-50$ & 5377.55 \\
Silty and sandy clay & $50-75$ & $0-25$ & $0-25$ & 8575.41 \\
Clay and sand & $50-75$ & $0-25$ & $50-75$ & 203.64 \\
Sand & $0-25$ & $0-25$ & $75-100$ & 1012.53 \\
Clayey sand & $25-50$ & $0-25$ & $50-75$ & 4133.09 \\
Silty sand & $0-25$ & $25-50$ & $50-75$ & 548.69 \\
Clayey and silty sand & $0-25$ & $0-25$ & $50-75$ & 9859.46 \\
Silt and sand & $0-25$ & $50-75$ & $50-75$ & 1157.72 \\
Silt & $0-25$ & $75-100$ & $0-25$ & 54.68 \\
Sandy silt & $0-25$ & $50-75$ & $25-50$ & 3708.85 \\
Clayey silt & $25-50$ & $50-75$ & $0-25$ & 2815.10 \\
Clayey and sandy silt & $0-25$ & $50-75$ & $0-25$ & 1114.35 \\
Sandy clay and silt & $25-50$ & $25-50$ & $0-25$ & 1800.69 \\
Silty sand and clay & $25-50$ & $0-25$ & $25-50$ & 940.88 \\
Clayey silt and sand & $0-25$ & $25-50$ & $25-50$ & 3.77 \\
Sand and silt and clay & $25-50$ & $25-50$ & $25-50$ & 9374.88 \\
\hline
\end{tabular}

improved results for silt; the ordinary kriging PSEs of clay and sand are slightly reduced. Fig. 6 presents the mean PSE values for ten-percentintervals of each grain size when applying ordinary kriging and cokriging. The comparison shows that cokriging delivered improved results (reduced PSEs) for silt and slightly improved results for clay and sand. Ordinary kriging achieved better prediction probabilities for gravel and was, therefore, used for further analysis. Cokriging was able to capture most of the small variations in the sediment texture distribution. Furthermore, reduced nugget-effects confirmed that the cost distance grid was a better indicator for sediment texture when compared to bathymetry and slope.

\subsection{Grain size maps and sediment texture map of the Beaufort Shelf}

Fig. 7 shows the results for sand, silt and clay raster calculations. The display of the measured values and the PSEs for each grain size provides quality control to the user (Fig. 7). The PSEs were also used to define the extent of a reliable interpolation area. The charts in Fig. 8 show the frequency of samples falling into the ten-percent-intervals of each grain size and their corresponding averaged errors of the predictions. The errors presented as error bars describe the deviation from the measured and the predicted values resulting from the cross-validation for each interval. They provide the sediment texture map with a comprehensible quality assessment showing, for instance, that best predictions were achieved for low sand and gravel contents (0-50\%) and intermediate silt and clay values (30-80\%). In contrast, there are considerable deviations in predicting high percentage values $(>80 \%)$ for all grain sizes.

The sediment texture map of the Beaufort Shelf in Fig. 8 was calculated according to the grain size classifications of Wentworth (1922) and Shephard (1954). Each cell contains the percentage of the three grain sizes and was applied to Shephard's (1954) classification

Table 3

Quality of estimation by means of cross-validation given by the mean standardized error (MSE), the ratio of mean squared cross-validation errors and the kriging variances (RMSSE), the correlation coefficient after Spearman $\left(C_{S}\right)$ and the nugget-sill ratios (N-S ratio). A comparison of ordinary kriging (OK) and cokriging (CK).

\begin{tabular}{|c|c|c|c|c|c|c|c|c|}
\hline & \multicolumn{2}{|l|}{ MSE } & \multicolumn{2}{|c|}{ RMSSE } & \multicolumn{2}{|l|}{$C_{S}$} & \multicolumn{2}{|c|}{$\mathrm{N}-\mathrm{S}$ ratio } \\
\hline & OK & CK & OK & CK & OK & CK & OK & CK \\
\hline Gravel & 0.00 & -0.01 & 0.99 & 0.96 & 0.88 & 0.74 & 0.13 & 0.25 \\
\hline Sand & -0.16 & -0.01 & 1.05 & 1.02 & 0.67 & 0.78 & 0.59 & 0.52 \\
\hline Silt & 0.02 & 0.01 & 0.94 & 0.99 & 0.87 & 0.93 & 0.24 & 0.09 \\
\hline Clay & 0.02 & 0.02 & 0.97 & 1.01 & 0.93 & 0.97 & 0.20 & 0.12 \\
\hline
\end{tabular}

system. The percentage values of the grain size composition and aerial coverage of each of the eighteen classes seen in Fig. 8 are given in Table 2. Colors generally are chosen as follows: silt in blue, clay in red, sand in yellow and mixed sediments in green. Gravel consists of a separate GIS layer and is overlaid as a gray hatched polygon.

\subsection{Quality assessment}

The maps in Figs. 7 and 8 are interpolation results and their purpose is to provide predicted seabed sediment texture values. The sediment distribution is the result of a defined and calculable probability based on PSE maps, and provides a guide to the distribution of sediment textures on the seabed. However, subsampling is necessary to provide ground truth for further seabed texture verification.

The PSE maps in Fig. 7 show an increasing quality of prediction from gravel to clay to silt to sand, respectively. The reason for this is the very distinctive distribution of gravel in the Beaufort Shelf. Large areas are gravel-free, thus, the requirements of the gravel cokriging model are comparably low. The other grain sizes show a slight trend: the smaller the grain size, the more precise the prediction of unsampled areas when applying the interpolation method (clay predictions are better than silt; silt predictions are better than sand). This is caused by varying degrees of homogeneity and similarity in the data values. When comparing sand, silt and clay, sand was the most demanding parameter for the prediction because the data distribution was affected by increased spatial small-scale variations (see a high value in the nugget-sill ratio in Table 3). The PSEs have been reduced by considering important influence factors as depth and slope, but mainly by the Mackenzie River's silt input and anisotropy.

\subsection{Comparison with Pelletier (1984) maps}

Pelletier (1984) published a comprehensive sediment atlas of the Beaufort Sea. Therein, he presents sediment maps of clay, silt, sand and gravel in $10 \%$ intervals but the method of mapping is not described. His sediment texture map also combines the four sediment grain sizes following Shephard's (1954) grain size classification system.

Both Pelletier's (1984) study and this study have used almost the same database for the time period 1969-1983. This study also includes recent data (1969-2008) which extends the data set, particularly in shallow areas close to the coast. To enable a direct comparison of the single grain size maps, the intervals for the grain size maps were classified according to those of Pelletier (1984) (see Fig. 9).

In general, the grain size maps show similar patterns, however, regional differences can be recognized from the map pairs. Pelletier (1984) highlights single measurements with considerable gradients by drawing circles around them, while kriging algorithms tend to smooth measured gradients (Fig. 9). The variogram values for gravel are suboptimal; Pelletier's (1984) method might present superior results than the interpolation method. This is caused by the sparse occurrence of gravel in the data set (from a statistical point of view) as well as a reduced correlation of gravel to the cokriging parameters (Fig. 6). Analyzing the sand map, some but not all of the Pelletier (1984) elongated ovals around single point data might be explained by artificial islands. When comparing the silt and clay map pairs, the variogram analyses were more reliable and this corroborates the frequency distribution of the grain size classes for the Beaufort Shelf (Fig. 3).

\section{Conclusions}

The geostatistical concept of kriging was used to predict and map the occurrences of sediment textures in the Beaufort Sea. Therefore, grain size raster maps were developed for a range of grain size data (clay, silt, sand and gravel) and then combined with each other by raster calculation. Cokriging provided superior interpolation results for silt, 


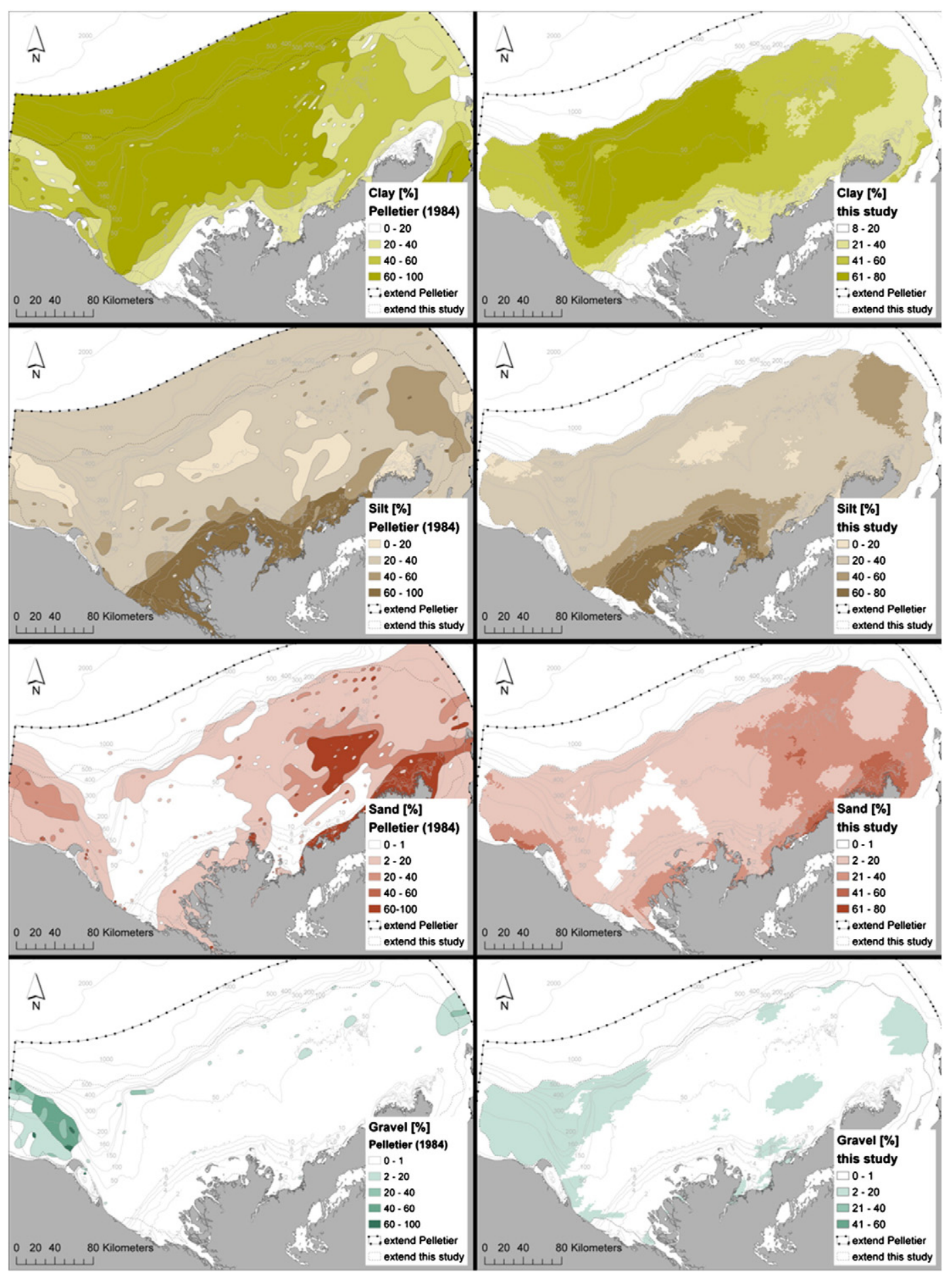

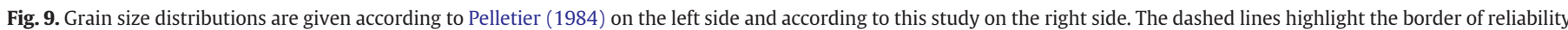
of the interpolated areas based on the interpolated results. Class ranges are consistent with those of Pelletier (1984) to enable a comparison between the two studies.

clay and sand compared to ordinary kriging by using secondary variables (bathymetry, slope and sediment input of the Mackenzie River). In general, the performance of geostatistical analysis and interpolation relies to a certain degree on expert knowledge. This knowledge is expressed in the analysis of the data set, the preprocessing to adapt it to the algorithm, and the tuning of the model's parameters to avoid any remaining difficulties. Nevertheless, especially in nearshore regions like the Beaufort Shelf, geostatistical interpolation techniques are very useful because the sampling is often difficult or impossible due to ice conditions or even prohibited near oil platforms.
The two main issues with the grain size datasets used in this study are the variability of the sampling method (grab samples and topmost layer of piston cores) and the variability in the resolution of information. Especially in the shallow areas, as in the Mackenzie Bay, the sampling is not very dense. Local events could have been missed. Nevertheless, the procedure of cokriging and ordinary kriging greatly enhanced interpolation estimates without additional sampling. This method, as well as the inclusion of recent data, provides an objective geostatistically interpolated surficial sediment texture map of the Beaufort Shelf which should be integrated with surficial mapping for future application. 
Sediment type distribution is closely linked with the discipline of benthic habitat mapping but also with geochemical properties of the sediments since increased methane contents e.g. are correlated with muddy sediments. Since textural or morphological classes are relevant to seabed ecology, the sediment type map (presented in Fig. 8) provides a geostatistical approach which could be used for benthic ecosystem mapping and for predictive occurrence of gassy sediments in the Beaufort Sea. Additionally, the interpolated grain size distribution maps can be used to supplement our understanding of sediment deposition, on the Beaufort Shelf.

\section{Acknowledgments}

I thank the Natural Sciences and Engineering Research Council Canada (NSERC) for granting a Visiting Fellowship in Canadian Government Laboratories as a part of the International Polar Year (IPY). I also appreciate Natural Resources Canada (NRCan) for providing the sediment grain size data (Expedition Database NRCan). Thanks to my colleagues at the Geological Survey of Canada, Atlantic K.A. Jenner, V.E. Kostylev and S.M. Blasco for fruitful discussions. I would like to send special thanks and thoughts to S.M. Solomon who tragically passed away during this study.

\section{References}

Canadian Hydrographic Service, 1986. Beaufort Sea plotting base. Geological Survey of Canada. Open File 1388; 1 sheet.

Davis, J.C., 2002. Statistics and Data Analysis in Geology, 3rd ed. John Wiley and Sons New York, p. 638.

Dewis, F.J., 1971. Relationship between mineralogy and trace element chemistry in sediments from two fresh water deltas and one marine delta within the Mackenzie River drainage basin. M. Sc. Thesis, University of Calgary, Alberta, pp. 83.

EBA Engineering Consultants Ltd., 1976. Report on Offshore Pipeline Activities 1975-1976. Beaufort-Delta Oil Project Limited, Part 2. Volumes I and II of III.

Expedition Database (ED), 2010. NRCan; GSCA Sedimentology Lab Analysis (January 2010). http://ed.gdr.nrcan.gc.ca/GSC/ed-f-sedlab_1.cgi.

Forest, A., Sampei, M., Hattori, H., Makabe, R., Sasaki, H., Fukuchi, M., Wassmann, P. Fortier, L., 2007. Particulate organic carbon fluxes on the slope of the Mackenzie Shelf (Beaufort Sea): physical and biological forcing of shelf-basin exchanges. J. Mar. Syst. 68 (1-2), 39-54.
Goovaerts, P., 1997. Geostatistics for Natural Resources Evaluation. Oxford University Press, New York. 512 pp.

Harper, J.R., 1990. Morphology of the Canadian Beaufort Sea coast. Mar. Geol. 91, 75-91. Henry, R.F., 1975. Storm surges. Environment Canada, Beaufort Sea Project, Technical Report 19, p. 41

Hill, P.R., Blasco, S.M., Harper, J.R., Fissel, D.B., 1991. Sedimentation in the Canadian Beaufort Shelf. Cont. Shelf Res. 11, 821-842.

Hill, P.R., Lewis, C.P., Desmarais, S., Kauppaymuthoo, V., Rais, H., 2001. The Mackenzie Delta: sedimentary processes and facies of a high-latitude, fine-grained delta. Sedimentology 48 (5), 1047-1078.

Isaaks, E.H., Srivastava, R.M., 1992. An Introduction to Applied Geostatistics. Oxford University Press, p. 561.

Jenner, K.A., Hill, P.R., 1998. Recent, arctic deltaic sedimentation: Olivier Islands, Mackenzie Delta, North-West Territories, Canada. Sedimentology 45, 987-1004.

Kauppaymuthoo, V., 1997. Etude de la Dynamique Sedimentaire Hivernale du Delta du Mackenzie au Niveau de Kugmallit Bay. M.Sc. Thesis, Universite du Quebec a Rimouski, Canada.

Kerfoot, H., 1976. Radium Express 76 sediment samples and locations found in a field notebook provided by Dr. H. Kerfoot. NRCan (Atlantic).

Klohn-Crippen, 1998. DynaMAC Molikpaq Ice Loading Experience. PERD/CHC Report 14-62, Calgary, Alberta, Canada.

Krige, D.G., 1951. A statistical approach to some basic mine valuation problems on the Witwatersrand. J. Chem. Metall. Min. Soc. South Afr. 52 (6), 119-139.

Macdonald, R.W., Solomon, S.M., Cranston, R.E., Welch, H.E., Yunker, M.B., Gobeil, C., 1998. A sediment and organic carbon budget for the Canadian Beaufort Shelf. Mar. Geol. 144, 255-273.

Matheron, G., 1963. Principles of geostatistics. Econ. Geol. 58, 1246-1266.

O'Brien, M.C., Macdonald, R.W., Melling, H., Iseki, K., 2006. Particle fluxes and geochemistry on the Canadian Beaufort Shelf: implications for sediment transport and deposition. Cont. Shelf Res. 26, 41-81.

Pelletier, B.R., 1984. Marine science atlas of the Beaufort Sea sediments. Geological Survey of Canada. Miscellaneous Report 38.

Pesch, R., Pehlke, H., Jerosch, K., Schröder, W., Schlüter, M., 2008. Using decision trees to predict benthic communities within and near the German Exclusive Economic Zone (EEZ) of the North Sea. Environ. Monit. Assess. 136, 313-325.

Shephard, F.P., 1954. Nomenclature based on sand-silt-clay ratios. J. Sediment. Res. 24 (3), 151-158.

Walker, T.R., Grant, J., Jarvis, P., 2008. Approaching freshet beneath landfast Ice in Kugmallit Bay on the Canadian Arctic Shelf: evidence from sensor and ground truth data. Arctic 6 (1), 76-86.

Wentworth, C.K., 1922. A scale of grade and class terms for clastic-sediments. J. Geol. 30, 377-392. 